\title{
LINEAR NEVUS SEBACEOUS SYNDROME - RADIOLOGICAL FINDINGS
}

\author{
Pushpa Ranjan ${ }^{1}$, Shashwat Priyadarshi
}

${ }^{1}$ Senior Resident, Department of Radiology, IGIMS, Patna, Bihar.

2DNB 1 (Std), Department of Radiology, IGIMS, Patna, Bihar.

ABSTRACT

\section{BACKGROUND}

Linear nevus sebaceous syndrome is a rare neurocutaneous syndrome characterised by epidermal nevus and variety of congenital abnormalities, predominantly of CNS. Clinically, it is presented as developmental delay, delay in milestone of development and mental retardation. Here, we presented two case reports with radiological findings.

\section{KEYWORDS}

Central Nervous System, Hemimegalencephaly, Nevus.

HOW TO CITE THIS ARTICLE: Ranjan P, Priyadarshi S. Linear nevus sebaceous syndrome - radiological findings. J. Evolution Med. Dent. Sci. 2016;5(85):6354-6356, DOI: 10.14260/jemds/2016/1436

\section{BACKGROUND}

Linear nevus sebaceous syndrome is a rare sporadic complex disorder characterised by linear epidermal nevus and various congenital abnormalities including predominantly CNS and others are connective tissue, skeletal system, cardiac and ocular malformations. Hemimegalencephaly is the most commonly found abnormality, others are neuronal migration abnormalities - patchy macrogyria, microgyria, heterotopias, etc., agenesis of corpus callosum, myelomeningocele, DandyWalker syndrome, Arnold-Chiari malformation and tumours have found.(1) Seizure is the most common clinical presentation. CT and MRI play an important role in delineating structural abnormalities of CNS.

\section{CASE 1}

A 7-year-old girl patient presented with facial disfigurement (Facial asymmetry) and she is referred for USG (Radiology Department) to rule out any obvious lesion. On examination, there is facial asymmetry. Slightly curved nevus extending from left lateral canthus to down the left cheek. There is history of seizure and learning problem in school. No history of developmental delay and mental retardation. Birth history and family history was uneventful. On USG of left cheek, there was hypertrophy of subcutaneous tissue including fat underlying the nevus (Fig. 3). On x-ray no gross abnormality was seen, only thickened and hypertrophied soft tissue seen over affected left side of face (Fig. 4).

On CT scan and MRI, hemimegalencephaly noted on left cerebral hemisphere (Fig. 6, 7). There is hypertrophy of subcutaneous tissue underlying the nevus on left side.(2,3) Illdefined lytic lesion noted on left mandible, maxilla and thickening of calvaria on left side, especially the left frontal bone (Fig. 6).

Financial or Other, Competing Interest: None.

Submission 12-09-2016, Peer Review 10-10-2016,

Acceptance 17-10-2016, Published 24-10-2016.

Corresponding Author:

Dr. Pushpa Ranjan,

Flat No. 403, Block - F,

Terrace Gardenia,

Near Laddoo Gopal Sweets,

Ashiyana Digha Road,

Patna-800014, Bihar.

E-mail: pushpa.rajeevranjan@gmail.com

DOI: $10.14260 /$ jemds $/ 2016 / 1436$

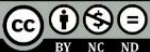

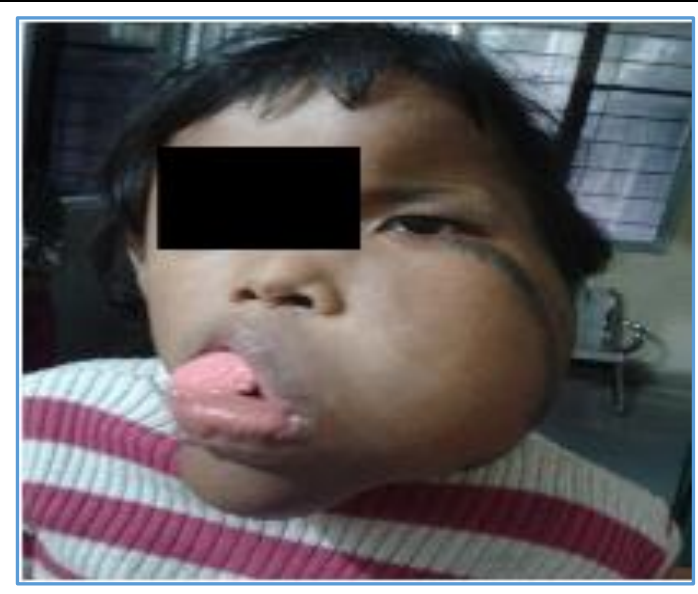

Figure 1. Facial Asymmetry with Hemihypertrophy of Left Side of Face with Epidermal Nevus Extending from Left Lateral Canthus to Down the Left Cheek

\section{CASE 2}

A three years old boy already diagnosed with linear nevus sebaceous syndrome is sent to Department of Radiology to rule out any congenital abnormality. On examination, there is facial asymmetry with hypertrophy on left side of face and nevus on left cheek. There was history of seizure. Birth history was unremarkable. On CT and MRI, there was evidence of hemimegalencephaly (Fig. 4). No other gross abnormality was detected.

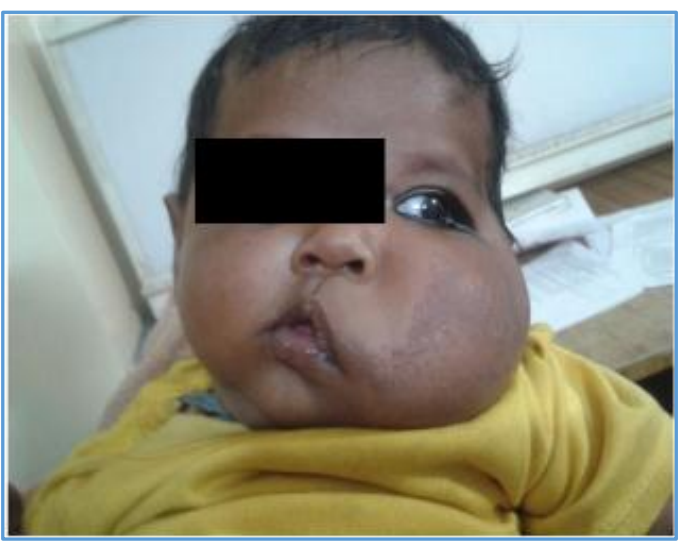

Figure 2. Facial Asymmetry with Hemihypertrophy of Left Side of Face with Epidermal Nevus over Left Cheek 


\section{DISCUSSION}

Linear nevus sebaceous syndrome is a rare sporadic complex syndrome characterised by skin lesion and many extracutaneous abnormalities affecting many system, predominantly CNS. LNDD first described by Schimmelpenning and subsequently by Feuerstein and Mims. (4) Both nevi and syndrome have been described under many names - Jadassohn nevus phacomatosis, nevus unius lateris, organoid nevus syndrome, Solomon syndrome.(2)

The incidence of sebaceous nevi at birth is estimated at 1 in 1000, but prevalence of these lesions in association with other anomalies as in case of LNSS varies between case reports to around 1 in 10,000 (6-orphanet).

Epidermal nevi arise from basal layer of embryonic epidermis and are considered as congenital hamartomatosis malformation. These lesions most often visible at birth, but may appear during childhood.(2) Linear sebaceous nevus first described by Jadassohn in 1895.(4) A paramedian location nevus is typically vertical in orientation.

Overgrowth of tissue is part of the spectrum of abnormalities seen in LNSS and commonly involve bones of skull and face and tissue such as fat and connective tissue.

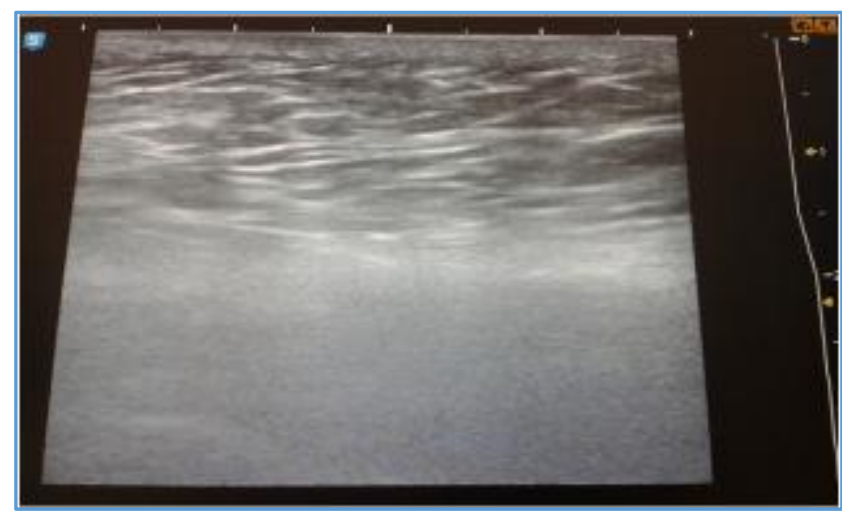

Figure 3. USG of Left Hypertrophy of Face show Overgrowth of Soft Tissue including Subcutaneous Fat and Connective Tissue

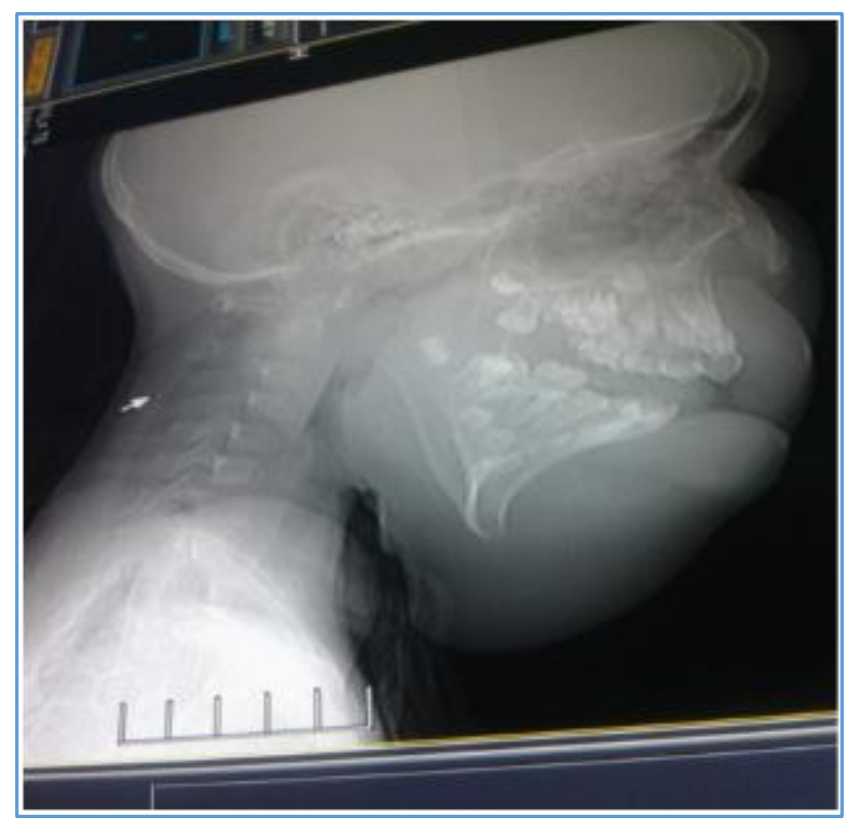

Figure 4. Lateral X-Ray of Face show Overgrowth of Soft Tissue over Left Jaw and Prominence Middle Part of Mandible

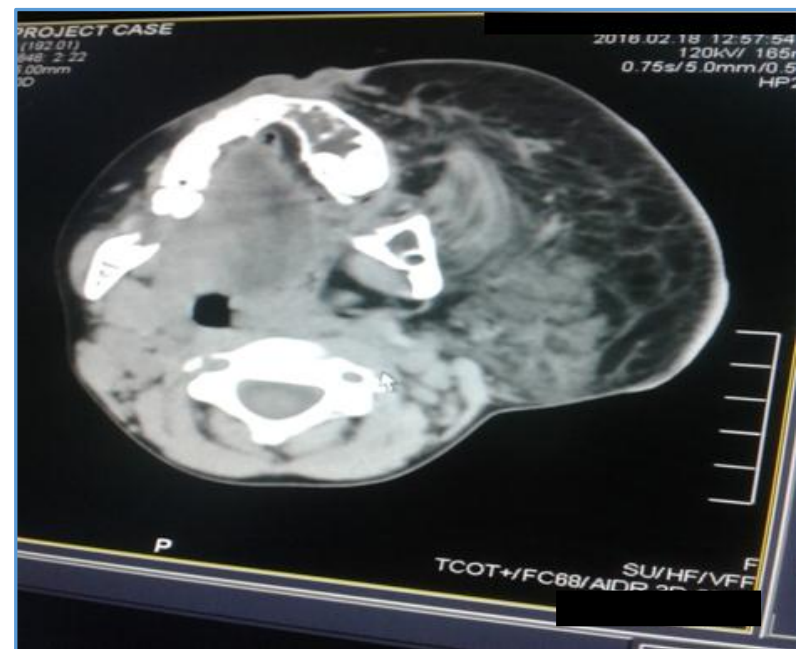

Figure 5. Axial Non-Contrast CT Scan of Face shows Overgrowth of Soft Tissue of Left Side of Face with IIIDefined Expansile Lytic Lesion on Left Side of Mandible

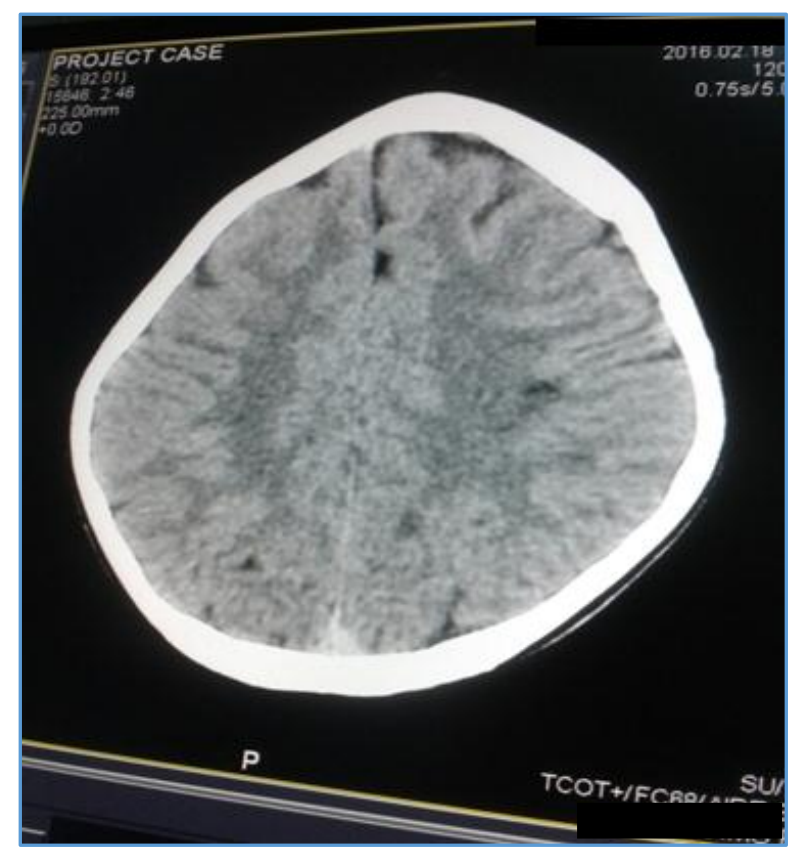

Figure 6. Axial Non-Contrast CT Scan of Brain shows Hemimegalencephaly involving Left Cerebral Hemisphere with Midline Shift of Left Frontal Lobe and Thickening of

Calvaria of Left Side especially in Left Frontal Bone

Among extracutaneous abnormalities, CNS is involved in $50 \%$ of cases.(2) Clinical manifestation is seizure, delay in milestone of development and mental retardation. Seizures are focal and may present as infantile spasm. Usually, they are refractory and require hemispherectomy.(5) In radiological imaging (CT and MRI), most common finding is unilateral hemimegalencephaly seen ipsilateral to epidermal nevus. This rare brain malformation is thought to be a result of abnormal neuronal migration.(2) Radiographic feature of hemimegalencephaly is enlargement of all or part of one cerebral hemisphere, enlargement of ipsilateral lateral ventricle, agyria, polygyria, increased volume of white matter with gliosis on affected side. On T2 weighted study, increased signal intensity of white matter in affected hemisphere (Fig. 7). 


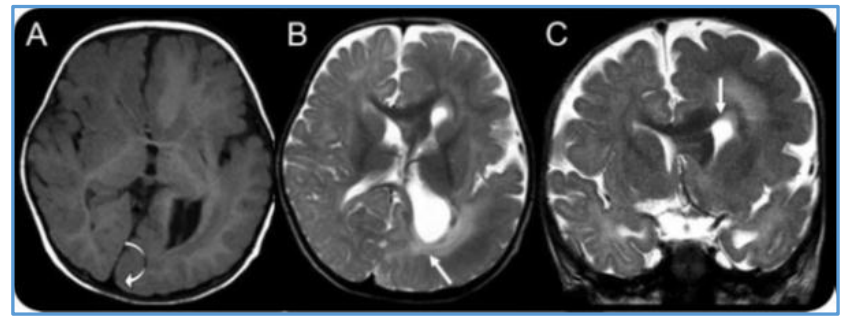

\section{Figure 7. Axial T1 (a) and Axial and Coronal T2 Weighted $(B, C)$ Image of Brain show Enlargement of Left Cerebra Hemisphere (Hemimegalencephaly) and Colpocephaly}

Pathologically, hemimegalencephaly is characterised by complete disorganisation of cortical cytoarchitecture without normal cortical layer and area of cortex is smaller than contralateral side, suggesting abnormal proliferation of the white matter as the mechanism of hemispheric enlargement.(5)(6)

Abnormalities affecting other parts of body are connective tissue, skeletal system, cardiac and ocular abnormalities. Ocular abnormalities occur in 33\% of patients with LNSS(4) and include coloboma of lid, iris and chorioretinal colobomas, generalised retinal degeneration, antimongoloid lid fissure, asymmetry of orbit bone.(3)(7) Cardiac anomalies include coarctation of aorta and ventricular septal defect. With increasing age there is increased incidence of skin, breast, salivary gland, stomach, oesophagus and bladder cancer.(8)(9)

\section{CONCLUSION}

LNSS is a rare neurocutaneous syndrome. Among other organs, CNS is the most common affected organ. Hemimegalencephaly is the most common CNS abnormality.
Patients present with seizure, delay in milestone of development and mental retardation. In LNSS radiological imaging, (CT and MRI) play most important role in evaluation of extent of involvement of CNS and other organ.

\section{REFERENCES}

1. Zhang $W$, Simos PG, Ishibashi $H$, et al. Neuroimaging features of epidermal nevus syndrome. AJNR Am J Neuroradiol 2003;24(7):1468-70.

2. Cavenagh EC, Hart BL, Rose D. Association of linear nevus sebaceous nevus syndrome and unilateral megalencephaly. AJNR 1993;14(2):405-8.

3. Insler MS, Davlin L. Ocular findings in linear sebaceous nevus syndrome. British Journal of Ophthalmology 1987; 71(4):268-72.

4. Leonidas JC, Wolpert SM, Feingold M, et al. Radiological features of linear nevus sebaceous syndrome. AJR 1979; 132(2):277-9.

5. Pauline L, Kannan B, Suravannan V, et al. Linear nevus sebaceous syndrome. Annals of Indian Academy of Neurology 2014;17(4):468-9.

6. www.orpha.net/consor/cgi-bin/OC_Exp.sphp ?Lng=GB\&exprt.

7. Schwartz RA, James WD. Epidermal nevus syndrome, clinical presentation, physical, causes. Emedicine 2016. medscape.com/article/1117506.

8. Schwartz RA, James WD. Epidermal nevus syndrome workup: imaging studies and other tests and histologic findings. Emedicine 2016. medscape. com/article/ 1117506.

9. Surve TY, Muranjan MN, Deshmukh CT, et al. Inflammatory linear verrucous epidermal nevus syndrome with bilateral vertebral artery occlusion. Indian Pediatr 1999;36(8):820-3. 